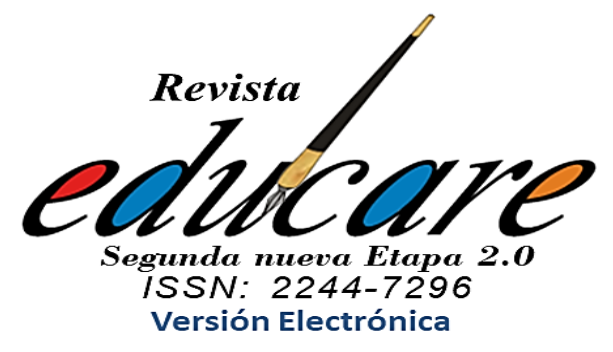

Volumen 25 No. 2 Mayo - Agosto 2021

(237-255)

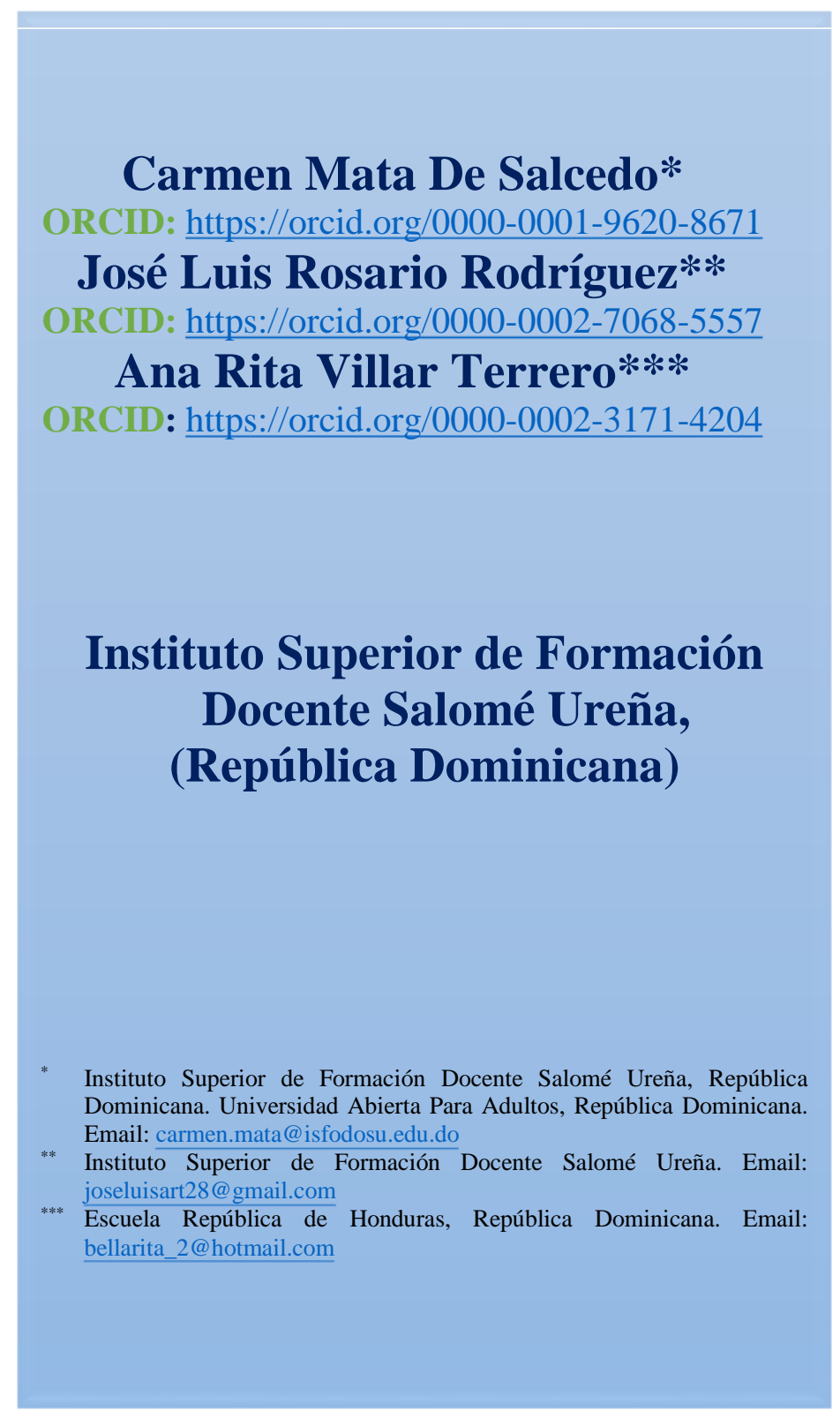

\title{
EL CORTOMETRAJE COMO HERRAMIENTA PEDAGÓGICA PARA EL TRABAJO COLABORATIVO EN ESTUDIANTES DEL ISFODOSU
}

THE SHORT FILM AS A PEDAGOGICAL TOOL FOR COLLABORATIVE WORK IN ISFODOSU STUDENTS

Recibido:

28-03-2021

Aceptado:

19-07-2021 


\section{Introducción}

A partir de varios procesos de observación en la asignatura Taller de Cineforum impartida en el período académico enero-abril 2021 en el Instituto Superior de Formación Docente Salomé Ureña (ISFODOSU), Recinto Luis Napoleón Núñez Molina, se evidenció que un grupo de estudiantes cursantes de la Licenciatura en Matemáticas orientada a la Educación Secundaria presentaban dificultades para trabajar en equipo, influyendo algunos factores como la procedencia de estos de diversos lugares, manifestando costumbres y comportamientos, manera de pensary actuar diferentes, generando poca empatía, lo que ocasionó conflictos entre ellos para trabajar en equipo.

En este sentido, el docente les orienta sobre la importancia de interactuar y debatir la temática, algunos educandos expresaron que eran muy inteligentes y que ya se entendían, alegando razones para no juntarse con otros distintos o en el peor de los casos para trabajar solos. Al momento de la conformación de los grupos existían líderes estudiantiles fijos y que se realizaba lo que ellos sugerían, evidenciando una especie de autoritarismo. Además, mostraban poco interéspor el taller, expresando que era una pérdida de tiempo y que esto no aportaba nada para sus fines educativos y que más bien, les quitaría tiempo para realizar sus tareas.

No obstante, utilizaban de forma continua sus teléfonos móviles, distrayéndose con contenidos no académicos, generando un irrespeto hacia el docente y la clase. Es por ello que se hace necesario implementar el cortometraje, como herramienta innovadora, el cual constituye una estrategia que permite la integración de los estudiantes y la disposición para trabajar de forma colaborativa, tomando en cuenta lo que les llama la atención, gracias a que los equipos tecnológicos son más comunes y accesibles, estos pueden rodar sus propios cortometrajes sin tantos recursos técnicos ni económicos. Así, con sus dispositivos móviles, cámaras de uso doméstico y algún software libre y gratuito, pueden editar diversos videos, creando producciones de manera fácil, sencilla y rápida. 


\section{Argumentación Teórica}

\section{El cortometraje como herramienta pedagógica}

El cortometraje es una técnica de animación que consiste en tomar fotografías de un objeto, haciendo ligeros cambios en su posición o en su forma, para que, al reproducir todas las imágenes como una serie continua, se obtenga la ilusión de movimiento. Se utiliza la grabación"fotograma a fotograma". Como recurso educativo ofrece múltiples posibilidades con las que hacer más motivador y completo el aprendizaje. Para Fernández y Barreira (2017):

El cortometraje es una técnica de animación que consiste en tomar fotografías de un objeto, haciendo ligeros cambios en su posición o en su forma, para que, al reproducir todas las imágenes como una serie continua, se obtenga la ilusión de movimiento. Se utiliza la grabación "fotograma a fotograma". Como recurso educativo ofrece múltiples posibilidades con las que hacer más motivador y completo el aprendizaje (p.31)

En tal sentido, la realización de un cortometraje supone un trabajo de equipo, en el que la cooperación de todos y cada uno de sus miembros es uno de los rasgos más significativos. Así, los estudiantes valoran el sentido del grupo no sólo cuando están todos juntos, también cuando nadie se queda fuera y por cuanto todos aportan una parte. El uso de la técnica del cortometraje como herramienta pedagógica es vinculante a la práctica real en el aula, puesto que mejora la potencialidad en el alumnado de altas capacidades, posibilitando la aplicación de una metodología activa, de aprendizaje por competencias, de innovación y mejora de los procesos y los resultados de los estudiantes, lo cual resulta favorable para el aprendizaje colaborativo en el aula.

\section{Aprendizaje colaborativo}

Revelo-Sánchez, Collazos-Ordoñez y Jiménez-Toledo (2018), señalan:

... surge el constructor de aprendizaje colaborativo. Este se sustenta en enfoques cognitivistas. Si se parte de una enseñanza centrada en el estudiante, cómo promueve el constructivismo, se tiene cuenta lo que pasa al interior de cada aprendiz, pero también la forma conjunta y social de promover los aprendizajes nuevos y engancharlos con los que ya existen para crear una estructura de pensamiento cada vez más pertinente con los procesos de enseñanza y aprendizaje. No solo importa el producto; son importantes también los 
procedimientos y rutas para la consecución de nuevos saberes. De ahí la referencia al constructivismo social como el eje central de este enfoque... (p.5).

El aprendizaje colaborativo es el empleo didáctico de grupos reducidos en los que los estudiantes trabajan juntos para maximizar su propio aprendizaje y el de los demás. La cooperación consiste en trabajar juntos para alcanzar objetivos comunes. Es así como el cortometraje es una herramienta pedagógica que fomenta el trabajo colaborativo, puesto que amerita procesos de comunicación, coordinación, complementariedad, compromiso y confianza para lograr la meta del video, lo cual desarrolla el aprendizaje autónomo, la curiosidad natural, el pensamiento creativo, el juicio crítico, la autocrítica y autoevaluación, la autoestima, las relaciones personales y la inclusión a través de una metodología colaborativa, que fortalezca el proceso pleno, armónico e integral de los estudiantes (Revelo-Sánchez et al. 2018).

Hoy en día, se promueve el desarrollo de prácticas colaborativas que ayudan a que los actores del proceso educativo utilicen sus habilidades en beneficio del colectivo. Esta manera de abordar la formación es importante, ya que constituye un método de aprendizaje interactivo que precisa de esfuerzos, talentos, responsabilidad, desarrollo de competencias e invita a participary construir juntos sus conocimientos.

Muchos estudios se han realizado sobre el trabajo colaborativo por ser una estrategia que ha impactado de manera positiva en los procesos educativos. Uno de ellos realizado por el Programa para la Evaluación Internacional de Alumnos (PISA, 2015) y la Organización para la Cooperación y Desarrollo Económico (OCDE, 2016), quienes señalan que resulta de vital importancia que el estudiante sea capaz para desarrollar el trabajar en cooperación y colaboración, puesto que favorece la resolución de problemas.

\section{Trabajo colaborativo}

Jarauta (2014) expresa:

El trabajo colaborativo conlleva a la obtención de beneficios de manera muy amplia ya que a través desarrollan capacidades intelectuales, así como profesionales mediante el análisis y reflexión, se adquiere de igual manera un conocimiento académico, se desarrolla un sentido creativo para dar solución a las problemáticas que se presentan, sefortalece las capacidades de comunicación y autonomía y desde luego un crecimiento personal. (p.285). 
Se debe destacar los beneficios que tiene esta estrategia si se emplea en el proceso de enseñanza y aprendizaje, a fin de que los docentes en formación desarrollen nuevas destrezas y actitudes que les permitan ser más innovadores y relativos, lo que le permitirá actuar ante situaciones de la vida cotidiana como del ámbito educativo, fomentando las relaciones interpersonales, asumiendo roles y responsabilidades que involucran a todos los participantes del grupo.

\section{Proceso de las distribuciones grupales}

De acuerdo a García y Abaurrea (2017), el proceso de las distribuciones grupales es aquel que permite que sean una herramienta imprescindible en el abordaje de actividades y tareas, a fin de adaptarse a las características y necesidades de aprendizaje del educando. En tal sentido, la idea central de los agrupamientos es que cada alumno obtenga una respuesta justa, logrando empatía en los mismos y favoreciendo la integración y socialización, siendo flexibles y la movilidad entre los grupos debe estar siempre garantizada.

\section{Trabajo colaborativo a través de la producción audiovisual de temáticas sociales}

Se hace énfasis en la necesidad de internalizar lo aprendido, lo cual, para Matos, Pasek y Rojas (2008), que amerita una comunicación abierta, un compartir, un interactuar, un liderazgo efectivo, el apoyo mutuo, la toma de decisiones compartidas, una sinergia en un ambiente cargado de armonía y valores que direccionen el trabajo en equipo para lograr no sólo lo planeado sino también una mayor participación activa entre los actores sociales en beneficio propio, de la escuela y comunidad.

Ante lo planteado, resulta necesario que se organicen varios cortometrajes en los distintos equipos de trabajo con temáticas sociales con el fin de despertar gran interés y participación entre todos los involucrados. La cooperación en las ideas y actividades a realizar puede generar mejora en los problemas comunitarios. Para procesos en colaboración, se pueden organizar mesas de trabajo que les permita compartir información y experiencias desde el material asignado. 


\section{Aspectos Metodológicos}

La presente investigación se desarrolló con base al paradigma cualitativo, bajo el método investigación-acción. Al respecto Martínez (2006) concibe la investigación cualitativa como: "El estudio de un todo integrado que forma o constituye primordialmente una unidad de análisis y que hace que algo sea lo que es, permitiendo analizar profundamente una realidad y su relación con los elementos que la constituyen”. (p. 66).

El estudio estuvo sustentado bajo el método investigación-acción, definido por Elliott (1993, p.88), como: ... "el estudio de una situación social para tratar de mejorar la calidad de la acción en la misma (...) En la investigación-acción, las "teorías" no se validan de forma independiente para aplicarlas luego a la práctica, sino a través de la práctica

La población estuvo conformada por diecinueve (19) estudiantes de la Licenciatura en Matemática, orientada a la Educación Secundaria, pertenecientes al Instituto Superior de Formación Docente Salomé Ureña, Recinto Luis Napoleón Núñez Molina, República Dominicana. Por ser la población finita, no se obtuvo muestra. Al respecto, Arias (2012) señala que la población finita es: “agrupación en la que se conoce la cantidad de unidades que la integran. Además, existe un registro documental de dichas unidades”. (p.82).

Con relación al procedimiento de investigación, está basado en el método inductivo, puesto que permite estudiar situaciones particulares, para llegar a conocimientos generales. Según Calduch (2014) "mediante este método se observa, estudia y conoce las características genéricas o comunes que se reflejan en un conjunto de realidades (...) este plantea que es un razonamiento ascendente que fluye de lo particular o individual hasta lo general”. (p.20).

Con base al modelo de investigación acción, se eligió el modelo de Kemmis, porque este permite organizar la investigación en un espiral de ciclos que contiene: el plan de acción, ejecución de la acción, la observación de la acción y la reflexiónde lo observado. La técnica empleada fue la observación participante que de acuerdo a Arias (2012): "En este caso el investigador pasa a formar parte de la comunidad o medio donde se desarrolla el estudio.” (p. 69).

Con respecto a los instrumentos, se abordaron la guía de observación, el formulario de diagnóstico, los registros anecdóticos, los encuentros virtuales, los diarios reflexivos, las 
fotografías, entre otros, que fueron reflejados mediante una bitácora de trabajo, que contiene las actividades realizadas de manera cronológica, así como las experiencias y actividades efectuadas durante la investigación.

Con relación al plan de acción, se describieron las fases del proceso de intervención. Para la Fase de planificación, se seleccionaron 4 contenidos de la asignatura Práctica Docente, se planearon tomando en cuenta lo propuesto por el programa de su plan de estudio de grado. Se realizó el plan general que contempla la fecha de intervención, los objetivos específicos, las actividadesy estrategias a desarrollas, los recursos utilizados, los nombres de los responsables, las técnicase instrumentos de observación y las técnicas e instrumentos para validar la información. Además, se redactaron las ideas en un plan específico que sirvió de guía al equipo investigador.

Para la fase de acción, se describieron todas las acciones de la intervención llevadas a cabo por momentos tal y como fueron planificadas en el plan y como fueron desarrolladas en la acción.Se describen las actividades realizadas en cada uno de los momentos de las intervenciones, sepresentan las técnicas usadas para el control de la acción y las técnicas de recogida de datos utilizadas.

Durante esta fase, se desarrollaron 4 intervenciones, cuyos objetivos fueron: Presentar el proyecto y describir las estrategias que se pueden utilizar para la producción de audiovisuales de manera creativa y colaborativa; Identificar y producir audiovisuales con temáticas sociales que favorezcan el trabajo en equipo; Publicar y compartir de forma vinculante con los medios de comunicación socialeslas producciones colaborativas de los estudiantes (ver Tabla I).

Para la fase de observación, se efectuaron 4 intervenciones, en el que los instrumentos que se utilizaron fueron la guía de observacióny el formulario de diagnóstico, además de las fotografías, las grabaciones de videos, el diario reflexivo y la matriz de evaluación de videos. Una vez finalizada la implementación del plan de acción para mejorar la capacidad de trabajo colaborativo, fue importante reflexionar sobre todo el proceso desarrollado. A modo general la problemática mejoró, debido a que se describieron algunas de las estrategias que se pueden utilizar para la producción audiovisuales de manera creativa y colaborativa, se identificaron y grabaron cuatro videos cortos con temáticas sociales que favorecieron el trabajo en equipo 
colaborativo, además de publicar y compartir de forma vinculante con varios medios de comunicación sociales las producciones colaborativas de los estudiantes. 


\section{PRESENTACIÓN DE LOS RESULTADOS Y HALLAZGOS}

Tabla 1.

Plan de acción

\begin{tabular}{|c|c|c|c|c|c|c|}
\hline Fecha e intervención & Objetivos específicos & Actividades & Estrategias & Recursos & $\begin{array}{c}\text { Técnicas e Instrumentos } \\
\text { deObservación }\end{array}$ & $\begin{array}{c}\text { Técnicas e Instrumentos } \\
\text { para } \\
\text { validar la información }\end{array}$ \\
\hline $\begin{array}{l}\text { Primera intervención } \\
\text { Miércoles } 10 \text { demarzo }\end{array}$ & $\begin{array}{l}\text { Describir las estrategias } \\
\text { que se pueden utilizar } \\
\text { parala producción de } \\
\text { audiovisuales de manera } \\
\text { creativa y colaborativa. }\end{array}$ & $\begin{array}{l}\text { - } \quad \text { Presentar el proyecto } \\
\text { Discutir sobre la estrategia a utilizar, presentar susposturas en } \\
\text { un foro de discusión. } \\
\text { Observación de videos de cortometrajes. Escribir en una } \\
\text { pizarra de colaboración interactiva (Padlet) sobreestrategias } \\
\text { que se pueden utilizar para la producción de audiovisuales de } \\
\text { manera creativa y colaborativa. } \\
\text { Conformación de } 4 \text { equipos utilizando las estrategiasdel } \\
\text { puzzle. Escribir en sus cuadernos fortalezas y debilidades } \\
\text { identificadas en el equipo conformado, agregar posibles } \\
\text { soluciones. }\end{array}$ & $\begin{array}{l}\text { Grupos dediscusión } \\
\text { Foro de discusión }\end{array}$ & 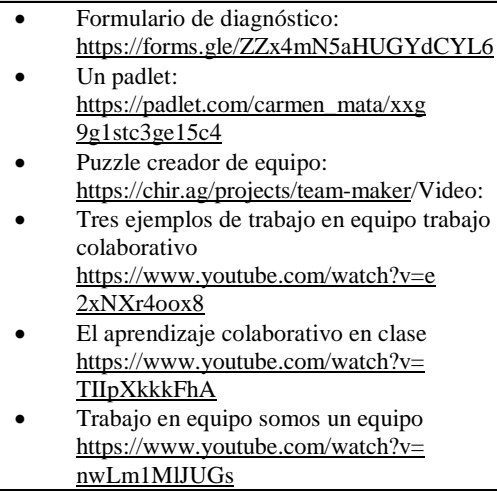 & $\begin{array}{l}\text { La guía de observación } \\
\text { El formulario de } \\
\text { diagnóstico. } \\
\text { Análisis documental } \\
\text { audiovisual: videoLas } \\
\text { fotografías y grabaciones } \\
\text { de videos. }\end{array}$ & $\begin{array}{l}\text { Triangulaciónde las } \\
\text { opiniones de los } \\
\text { observadores externos } \\
\text { Contrastar opinionessobre } \\
\text { videos Consenso }\end{array}$ \\
\hline
\end{tabular}

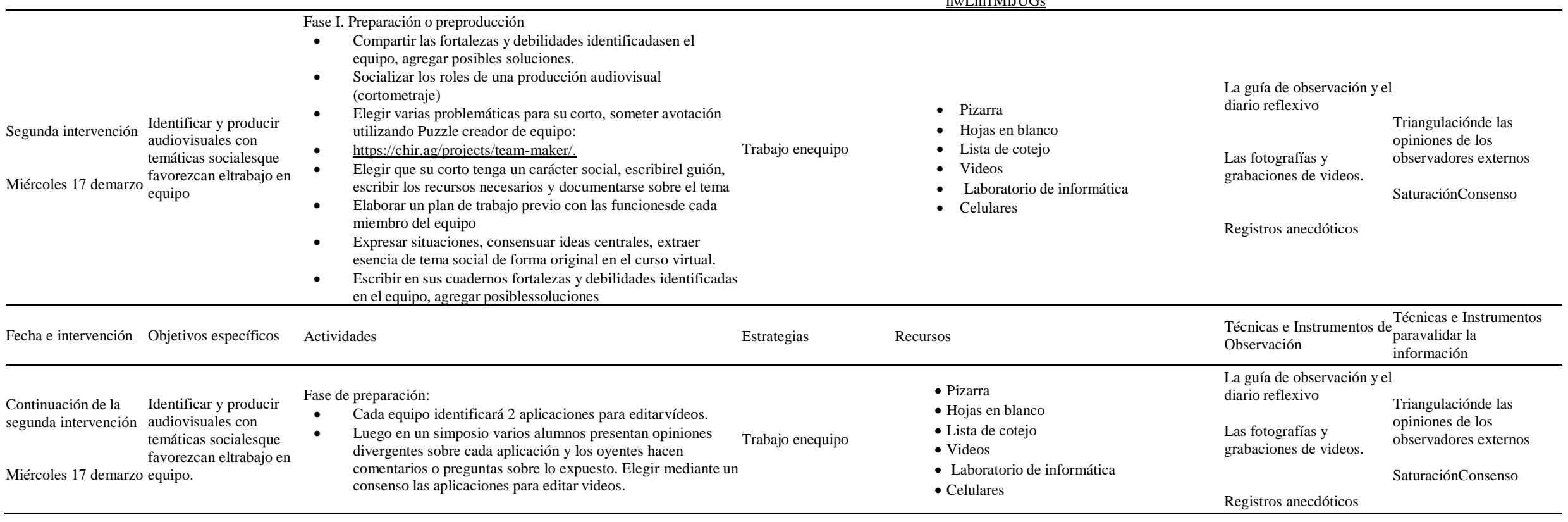


Tercera intervención Identificar y producir audiovisuales con

temáticas socialesque

Miércoles 24 demarzo favorezc

Fase 2. Rodaje

- Compartir las fortalezas y debilidades identificadasen el

equipo, agregar posibles soluciones.

- Leer el guión final y realizar un casting virtual paraelegir papel

Realizar un Role-playing donde los alumnos dramatizan

discuten lo observado y planteansoluciones en las distribuir las Role-playing es un

$$
\text { escenas }
$$

Continuación de Fase 2. Rodaje

dramatizacióndonde los

observado y plantea

Distribuir funciones para la grabación

- Celulares

- Vestuarios diverso

- Escenografías

- Utilería

Roles de la producción audiovisual

Iniciar grabación

Finalizar la grabación

Escribir en sus cuadernos fortalezas y debilidadesidentificadas

en el equipo, agregar posibles soluciones.

La guía de observación y el

diario reflexivo Triangulaciónde las

opiniones de los

observadores externo

grabaciones de videos.

Registros anecdóticos

SaturaciónConsenso
Fase 3. Finalización
$\bullet \quad$ Compartir las fortalezas y debilidades identificadasen el

forma vinculantertird medios de comunicación medios de comunicación

Compartir las fortalezas y debilidades identificadasen el

equipo, agregar posibles solucione

Presentar en el grupo clase

Promoción a través de link en sus redes sociales.

sociale

Presentar ante un público de la comunida

Escribir en sus cuadernos fortalezas y debilidades identificadas

estudiantes.
- Computadoras

- Celulares

- Comunida

- Redes sociales y plataformasdigitales.
La guía de observación y eldiario reflexivo E

formulario dediag

rabaciones de videos. La Contrastar opinionessobre

matrizde evaluación de videos Saturación

videos.

Fuente: Autores, 2021 
Tabla 2

Dimensiones observables

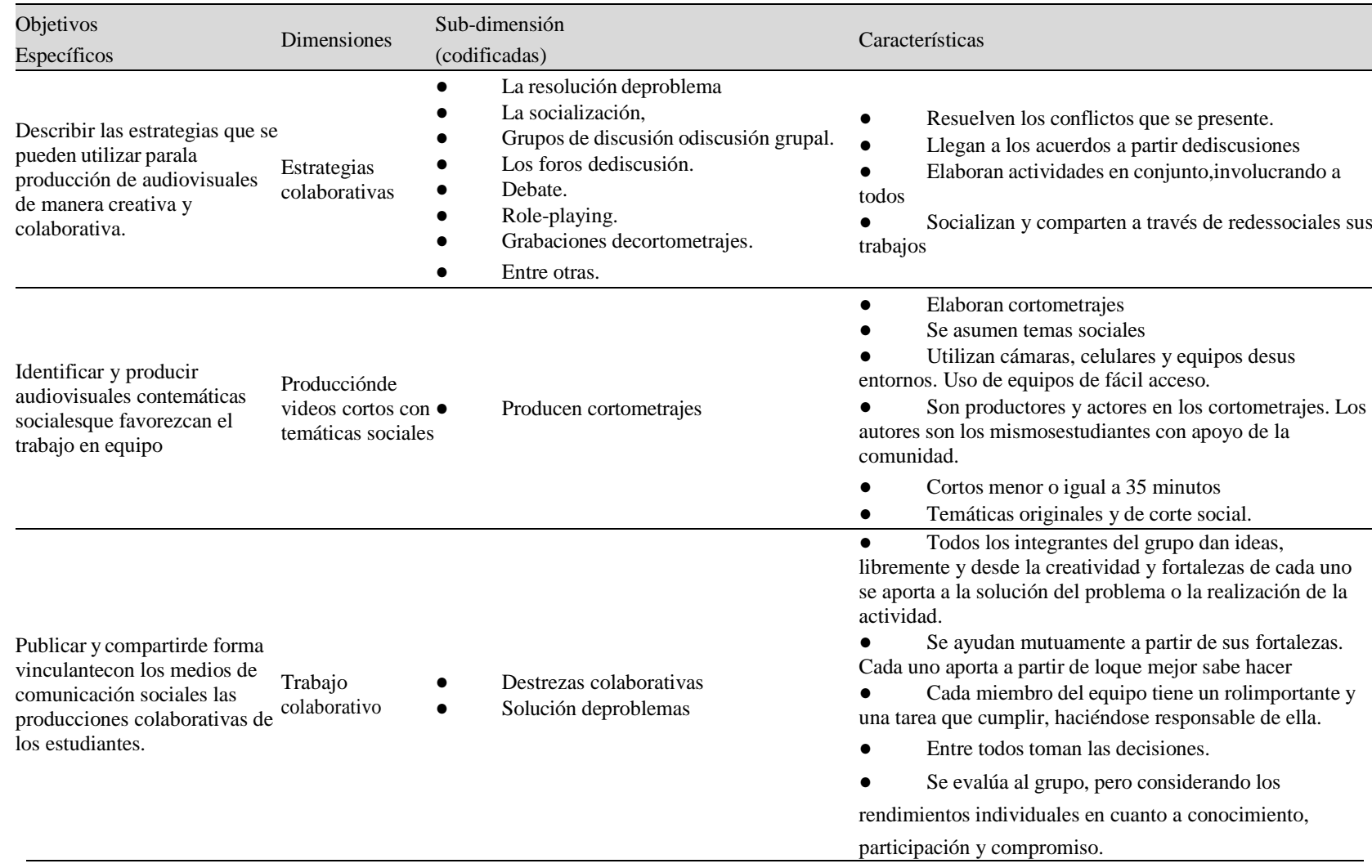

Fuente: Autores, 2021

\section{Triangulación de las informaciones (matriz de coherencia y discrepancia)}

Para identificar las estrategias que se pueden utilizar para la producción de audiovisuales de manera creativa y colaborativa se hizo necesario aplicar un instrumento diagnóstico a los estudiantes para que eligieran este tipo de estrategias, durante las intervenciones la investigadora utilizaba una guía de observación para registrar los sucesos. Otro dato que resaltar es que los estudiantes escribieron en un tablón de pizarra de colaboración interactiva (Padlet) sobre las estrategias que se pueden utilizar para la producción de audiovisuales de manera creativa y colaborativa. Los resultados arrojaron (ver Tabla No III) que las mismas son resolución de problema, tertulias, la socialización, grupos de discusión o discusión grupal, los foros de discusión, 
debate, role-playing, grabaciones de cortometrajes, entre otras.

\section{Tabla 3}

Estrategias colaborativas para la producción de audiovisuales

\begin{tabular}{|c|c|c|c|c|c|c|c|}
\hline Objetivo & Dimensiones & $\begin{array}{l}\text { Sub } \\
\text { dimensiones }\end{array}$ & $\begin{array}{l}\text { Opiniones de los } \\
\text { estudiantes }\end{array}$ & $\begin{array}{l}\text { Opiniones del } \\
\text { equipo } \\
\text { investigador }\end{array}$ & $\begin{array}{l}\text { Opiniones de } \\
\text { Expertos }\end{array}$ & Coincidencias & Discrepancias \\
\hline $\begin{array}{l}\text { Describir las } \\
\text { estrategias } \\
\text { que se } \\
\text { pueden } \\
\text { utilizar para } \\
\text { la } \\
\text { producción } \\
\text { de } \\
\text { audiovisuale } \\
\text { s de manera } \\
\text { creativa y } \\
\text { colaborativa. }\end{array}$ & $\begin{array}{l}\text { Estrategias } \\
\text { colaborativas }\end{array}$ & $\begin{array}{l}\text { La resolución } \\
\text { de problema } \\
\text { La } \\
\text { socialización. } \\
\text { Grupos de } \\
\text { discusión o } \\
\text { discusión } \\
\text { grupal. } \\
\text { Los foros de } \\
\text { discusión. } \\
\text { Debate. } \\
\text { Role-playing. } \\
\text { Grabaciones } \\
\text { de } \\
\text { cortometrajes } \\
\text { Entre otras. }\end{array}$ & $\begin{array}{l}\text { "la } \\
\text { dramatización, } \\
\text { el documental, } \\
\text { el cortometraje, } \\
\text { estrategias para } \\
\text { conformar } \\
\text { equipos son las } \\
\text { estrategias que } \\
\text { le gustan a mi" } \\
\text { "Las estrategias } \\
\text { que fomenten la } \\
\text { escucha y } \\
\text { expresión de } \\
\text { opiniones, como } \\
\text { las lluvias e } \\
\text { ideas" } \\
\text { "Estrategias que } \\
\text { nos permitan } \\
\text { organizar y } \\
\text { sistematizar las } \\
\text { opiniones e } \\
\text { ideas las } \\
\text { informaciones: } \\
\text { Cuadros, } \\
\text { matrices, } \\
\text { esquemas. } \\
\text { Estrategias para } \\
\text { la toma de } \\
\text { decisiones: } \\
\text { debates, } \\
\text { tertulias, mesa } \\
\text { redonda }\end{array}$ & $\begin{array}{l}\text { "Los estudiantes } \\
\text { resuelven los } \\
\text { problemas que } \\
\text { se presentan" } \\
\text { "Llegan } \\
\text { acuerdos a } \\
\text { partir de } \\
\text { discusiones" } \\
\text { "Elaboran } \\
\text { actividades en } \\
\text { conjunto, } \\
\text { involucrando a } \\
\text { todos". } \\
\text { "Hay unas } \\
\text { estrategias que } \\
\text { les gustan más } \\
\text { que otras. Lo } \\
\text { importante es } \\
\text { que fomenten la } \\
\text { colaboración" }\end{array}$ & $\begin{array}{l}\text { Oviedo, (2006,p.50), } \\
\text { "Es } \\
\text { importante utilizar } \\
\text { estrategias y en } \\
\text { actividades en las que } \\
\text { los alumnos tengan } \\
\text { que trabajar en equipo } \\
\text { e interactuar para } \\
\text { conseguir una meta } \\
\text { común". Dentro de las } \\
\text { estrategias } \\
\text { colaborativas se } \\
\text { encuentran: La } \\
\text { resolución de } \\
\text { problema, la } \\
\text { socialización, grupos } \\
\text { de discusión o } \\
\text { discusión grupal, los } \\
\text { forosde discusión, } \\
\text { debate, role- playing, } \\
\text { grabaciones de } \\
\text { cortometrajes entre } \\
\text { otras }\end{array}$ & $\checkmark$ & \\
\hline
\end{tabular}

Fuente: Autores, 2021

Las opiniones y expresiones iban en congruencias con lo observado por el equipo investigador, debido a que identificó que los estudiantes resolvieron los problemas que se presentaron, llegaron a distintos acuerdos a partir de discusiones, elaboraron actividades en conjunto, involucrando a todos a través de socializaciones. Cabe resaltar que había estrategias que les gustan más que otras como el caso del debate y los foros de discusiones. Lo importante es que unas u otras fomentaron la colaboración, la creatividad en sus producciones de cortometrajes.

En relación a la identificación y producción de audiovisuales con temáticas sociales que 
favorecen el trabajo en equipo. El contenido de la diversidad en distintos aspectos (motora, intelectual, visual y auditiva) ayudó que los estudiantes pensaran y comprendieran que los contenidos de caracteres sociales son muy importantes para el conocimiento de la comunidad,del país y del mundo. En ese orden, la experiencia llevada a cabo dejó como resultado la producción de cuatro cortometrajes que sirven para concientizar a las personas sobre esas temáticas sociales.

\section{Tabla 4}

Producción de audiovisuales con temáticas sociales

\begin{tabular}{|c|c|c|c|c|c|c|c|}
\hline Objetivo & Dimensiones & $\begin{array}{l}\text { Sub } \\
\text { dimensiones }\end{array}$ & Opiniones de losestudiantes & $\begin{array}{l}\text { Opiniones del } \\
\text { equipo } \\
\text { investigador }\end{array}$ & Opiniones deExpertos & Coincidencias & Discrepancias \\
\hline $\begin{array}{l}\text { Identificar y } \\
\text { producir } \\
\text { audiovisuales } \\
\text { con temáticas } \\
\text { sociales que } \\
\text { favorezcan el } \\
\text { trabajo en } \\
\text { equipo }\end{array}$ & $\begin{array}{l}\text { Producción de } \\
\text { audiovisuales } \\
\text { con temáticas } \\
\text { sociales }\end{array}$ & $\begin{array}{l}\text { Producen } \\
\text { cortometrajes } \\
\text { Temáticas } \\
\text { sociales: } \\
\text { Discapacidad } \\
\text { auditiva, } \\
\text { intelectual, moto } \\
\text { y visual }\end{array}$ & $\begin{array}{l}\text { "Todos pudimosculminar los videos } \\
\text { de cortometrajes dediversidad". } \\
\text { "Al principio parecía difícil,pero } \\
\text { cada unoasumió su rol" } \\
\text { "Cada video llevaun tema para que } \\
\text { las personas } \\
\text { reflexionen sobre la diversidad y } \\
\text { respeten a las personas con como } \\
\text { son" } \\
\text { "Se nos dañó el celular uno de los } \\
\text { celulares y seguimos con el de mi } \\
\text { apapá" } \\
\text { "Todo lo hicimosnosotros, } \\
\text { cualesquiera dudas nos ayudábamos } \\
\text { entre sí" } \\
\text { "El video más largo es el Ronycon } 6 \\
\text { minutos" }\end{array}$ & $\begin{array}{l}\text { "Elaboraron } 4 \\
\text { cortometrajes de } \\
\text { corte social" } \\
\text { "Utilizan cámaras, } \\
\text { celulares y } \\
\text { equiposde sus } \\
\text { entornos" } \\
\text { "Uso de equipos } \\
\text { defácil acceso". } \\
\text { "Son productores } \\
\text { yactores en los } \\
\text { cortometrajes". } \\
\text { "Sus videos fueron } \\
\text { menor de } 7 \\
\text { minutos" }\end{array}$ & $\begin{array}{l}\text { Es muy importantelo presentado por } \\
\text { Hartzler y Henry (2009), al indicar } \\
\text { que "los equipos necesitan la } \\
\text { participación de todos sus miembros } \\
\text {, para el logro de las metas de la } \\
\text { organización". Se deben realizar } \\
\text { prácticas que } \\
\text { permitan trabajar temáticas sociales } \\
\text { que le sirvan parala vida". } \\
\text { De acuerdo con García, Mena y } \\
\text { Sánchez (2011), cuando los } \\
\text { estudiantes "reflexionan sobre su } \\
\text { propia situacióny la de su entorno los } \\
\text { nconduce a la toma de concienciay } \\
\text { generar nuevos conocimientos desde } \\
\text { su propio accionar en sí y/o sobre sus } \\
\text { condicionantes". }\end{array}$ & $\checkmark$ & \\
\hline
\end{tabular}

Fuente: Autores, 2021

Una de las opiniones de los estudiantes, refleja que cada video es menor de 7 minutos lleva un tema para que las personas reflexionen sobre la diversidad y respeten a las personas tal como son. Un dato de interés es que la producción de esos cortometrajes no incurrió en gasto económico, sino que permitió que utilizan las cámaras de sus computadoras, laptop, celularesy equipos de sus entornos que son de fácil acceso". Lo que permitió que se convirtieran en productores y actores en los cortometrajes. Escribieron el guion, repartieron roles (ver tabla V. Roles desempeñados), seleccionaron la aplicación o herramienta de edición. Todo esto trajo como beneficioso la compenetración y colaboración como equipo, el desarrollo de la creatividad. Además del uso adecuado y educativo de las TICS. 


\section{Tabla 5}

Roles desempeñados en los cortometrajes

\begin{tabular}{|c|c|c|c|c|}
\hline Temasocial & Nombres de los autores & Roles Desempeñados & Video & Guion \\
\hline Auditiva & $\begin{array}{ll}\text { - } & \text { Maite Calderón } \\
\text { - } & \text { Erickson Rosario } \\
\text { - } & \text { Carlenis Caraballo } \\
\text { - } & \text { Lizberh Rodríguez }\end{array}$ & $\begin{array}{ll}\text { - } & \text { Maite Calderón: Edición, Guión, Elenco,Animación, Voces. } \\
\text { - } & \text { Erickson Rosario: Sonido, Guión, Elenco,Voces. } \\
\text { - } & \text { Carlenis Caraballo: Guión, Elenco, Voces. } \\
\text { Lizberh Rodríguez: Elenco, Voces. }\end{array}$ & $\begin{array}{l}\text { Cortometraje sobre la } \\
\text { Discapacidad Auditiva } \\
\text { https://www.youtube.com/w } \\
\text { atch?v=hovpW0vurDE }\end{array}$ & $\mathrm{Si}$ \\
\hline Intelectual & $\begin{array}{ll}\text { - } & \text { Rony Plasencia } \\
\text { - } & \text { Yarizamar Moronta } \\
\text { - } & \text { Abner David } \\
& \text { Rodríguez } \\
\text { - } & \text { Daniela Ferreira }\end{array}$ & $\begin{array}{l}\text { - } \quad \text { Rony Plasencia: Edición, Voces. } \\
\text { - } \quad \text { Yarizamar Moronta: Guión, Voces. } \\
\text { - } \quad \text { Daner David Rodríguez: Voces. } \\
\text { Daniela Ferreira: Voces. }\end{array}$ & $\begin{array}{l}\text { Discapacidad intelectual } \\
\text { https://www.youtube.com/w } \\
\underline{\text { atch?v=52DpNOaEgUM }}\end{array}$ & $\mathrm{Si}$ \\
\hline Motora & $\begin{array}{ll}- & \text { Kilsia Morales } \\
\text { - } & \text { Yolanni Peguero } \\
\text { - } & \text { Yordi Hidalgo } \\
\text { - } & \text { Jaribel Reyes }\end{array}$ & $\begin{array}{l}\text { - } \quad \text { Kilsia Morales: Edición, Montaje, Guión. } \\
\text { - } \quad \text { Yolanni Peguero: Producción, Guión. } \\
\text { - } \quad \text { Yordi Hidalgo: Narrador, Guión. } \\
\text { - Jaribel Reyes: Dirección General, Guión. }\end{array}$ & $\begin{array}{l}\text { El Despertar de un Nuevo } \\
\text { Sueño } \\
\text { https://www.youtube.com/w } \\
\text { atch?v=s1LfAR2oe-k }\end{array}$ & $\mathrm{Si}$ \\
\hline Visual & $\begin{array}{ll}\text { - } & \text { Jariel V. Kery } \\
\text { - } & \text { Kedwin R. Castillo } \\
\text { - } & \text { Andriely Bencosme } \\
\text { - } & \text { Melissa Vásquez } \\
\text { - } & \text { Nicole P. Núñez }\end{array}$ & $\begin{array}{l}\text { - Jariel V. Kery: Dirección General, Edición,Montaje. } \\
\text { - } \quad \text { Kedwin R. Castillo: Dirección General, Guión } \\
\text { Andriely Bencosme: Dirección General,Edición, Montaje, } \\
\text { Producción, Guión. } \\
\text { - } \quad \text { Melissa Vásquez: Dirección General Edición,Montaje, Voz. } \\
\text { Nicole P. Núñez: Dirección General Edición, Montaje }\end{array}$ & $\begin{array}{l}\text { Cortometraje, Conociendo el } \\
\text { mundo con otros sentidos. } \\
\text { https://www.youtube.com/w } \\
\text { atch?v=cgNPE9KJoqA }\end{array}$ & \\
\hline
\end{tabular}

Fuente: Autores, 2021

Después de realizados los cortometrajes, se hizo necesario publicar y compartir de forma vinculante con los medios de comunicación sociales las producciones colaborativas de los estudiantes, para ellos se eligieron plataformas y redes sociales que sirvieron para para promover sus trabajos, a su vez motivaban la visualizaron de los cortometrajes de suscompañeros, llegando a obtener varias reproducciones en poco tiempo. Lo que se traduce en motivación en las publicaciones. Durante esta práctica se observó un trabajo colaborativo, se ayudaban entre ellos, tantoasí que un equipo no sabía cómo compartirlo en YouTube y se ayudaron mutuamente (ver tabla No.8 opinión del equipo investigador). La intención de los proyectos sociales es conducir a la 
resolución de problemas a fin de satisfacer las necesidades del sujeto (Pérez, 2012).

Tabla 6

Trabajo colaborativo

\begin{tabular}{|c|c|c|c|c|c|c|}
\hline Objetivo & Dimensiones & $\begin{array}{l}\text { Sub } \\
\text { dimensiones }\end{array}$ & Opiniones delos estudiantes & $\begin{array}{l}\text { Opiniones del equipo } \\
\text { investigador }\end{array}$ & Opiniones deExpertos & Coincidencias Discrepancias \\
\hline $\begin{array}{l}\text { Publicar y } \\
\text { compartir de } \\
\text { forma } \\
\text { vinculante con } \\
\text { los medios de } \\
\text { comunicación } \\
\text { sociales las } \\
\text { producciones } \\
\text { colaborativas } \\
\text { de los } \\
\text { estudiantes. }\end{array}$ & $\begin{array}{l}\text { Trabajo } \\
\text { colaborativo }\end{array}$ & $\begin{array}{l}\text { Destrezas } \\
\text { colaborativas } \\
\text { Solución de } \\
\text { problemas }\end{array}$ & $\begin{array}{l}\text { "Sugiero quelo publiquemos en } \\
\text { YouTube" "También en nuestras } \\
\text { redessociales" } \\
\text { "es que hay gente que notrabaja, } \\
\text { perosi uno lo motiva se fajan" } \\
\text { "Que con susideas agilizaremosel } \\
\text { trabajo" } \\
\text { "algunos minimizan la importancia } \\
\text { de las planificaciones, esto } \\
\text { conduce a quedar atrapados en } \\
\text { hacerse amigos y descuidar el } \\
\text { rendimiento" " fue bueno poder } \\
\text { tratar de nueva forma con } \\
\text { compañeros que no había tenido la } \\
\text { oportunidad" } \\
\text { "Fortalezas: en este caso nos ayuda } \\
\text { a tener mejoresideas" } \\
\text { "para que losvieran en las redes } \\
\text { buscamos ayuda de todos los } \\
\text { compañeros de la sección, hasta de } \\
\text { la familia }\end{array}$ & $\begin{array}{l}\text { "Socializan y comparten a } \\
\text { través de redes sociales sus } \\
\text { trabajos, motivaban la } \\
\text { visualizaro n de los } \\
\text { cortometrajes de sus } \\
\text { compañeros" } \\
\text { "Hubo mucha motivación } \\
\text { en las publicaciones de su } \\
\text { trabajos" "Se observóun } \\
\text { trabajo colaborativ o, se } \\
\text { ayudaban entre ellos" "Un } \\
\text { equipono sabía cómo } \\
\text { compartirloen YouTube y } \\
\text { se ayudaronmutuament e" } \\
\text { a }\end{array}$ & $\begin{array}{l}\text { Pérez (2012), "los proyectos sociales hacen } \\
\text { referencia y se orientan a la resolución de } \\
\text { problemas para satisfacer las necesidades básicas } \\
\text { del individuo". } \\
\text { Marta y Gabelas (2012) cuando expresan que los } \\
\text { alumnos reconocen "que sus ideas, guiones, } \\
\text { historias, luego convertidas encortometrajes se } \\
\text { inspiran y recogen aquello que les llegade los } \\
\text { medios de comunicación social, y que esto, así } \\
\text { que influye, porque la moda, las tendencias, lo } \\
\text { que nos rodea es inevitable". Esto muestra que } \\
\text { experimentar con la TICs, con materiales } \\
\text { llamativos, metodologías, programas y recursos } \\
\text { novedosos, junto al trabajo colaborativo en el } \\
\text { proceso educativo fomentan mejores } \\
\text { competencias en los estudiantes. }\end{array}$ & \\
\hline
\end{tabular}

Fuente: Autores, 2021

Durante los encuentros, se solicitaron evidencias de las interacciones de los estudiantescomo equipos, lo que se pudo notar con los grupos WhatsApp, las capturas de pantallas de sus discusiones, sus expresiones en los encuentros sincrónicos, entre otros, lo que permitió verificar sus destrezas colaborativas, las cuales expresaban es que "ay gente que no trabaja", pero "si uno lo motiva se fajan", que con sus ideas agilizaremos el trabajo, algunos minimizan laimportancia de las planificaciones, esto conduce a quedar atrapados en hacerse amigos y descuidar el rendimiento, fue bueno poder tratar de nueva forma con compañeros que no habíatenido la oportunidad, una 
fortaleza en este caso nos ayuda a tener mejores ideas, para que losvieran en las redes buscamos ayuda de todos los compañeros de la sección, hasta de la familia.

\section{Conclusiones}

Las estrategias que se pueden utilizar para la producción de audiovisuales de manera creativa y colaborativa son la resolución de problemas, la socialización, los grupos de discusión o discusión grupal, el debate y los foros de discusión puesto que promovieron la interacción no sólo en el grupo general de clase en los encuentros sincrónicos, sino en los pequeños grupos colaborativos formados para cada uno loscortometrajes, favoreciendo las grabaciones de cuatro cortometrajes con temáticas sociales de autoría de los estudiantes, proceso que fortaleció el trabajo en equipocolaborativo, promoviendo así la creatividad de manera colaborativa.

El proceso de identificación y posterior grabación de temáticas sociales favorecieron en gran medida el trabajo en equipo colaborativo, debido a que para la selección se tomaron en cuenta elementos de interés para el colectivo. Ellas fueron la discapacidad auditiva, intelectual, motora y visual, vivencias y niveles de discriminación por falta de conocimientos en la comunidad.

Luego de evaluados los cortometrajes se procedió a publicar y compartir de forma vinculante con los medios de comunicación sociales, de manera específica en YouTube, Facebook, WhatsApp, entre otras, potenciándolo como una herramienta pedagógica. Además, estas producciones realizadas de forma colaborativa fueron promocionadas en la universidad, en donde se incentivaba el acceso a los links, observar el corto, dar likey dejar comentarios. Todo esto favoreció el compromiso y la calidad por el trabajo académico.

Sí se mejora la capacidad del trabajo colaborativo de los estudiantes mediante la estrategia de producción de cortometrajes, ya que se desarrollan estrategias colaborativas diversas, se resuelven conflictos, se seleccionan temáticas de cortesocial que motivan y dejan resultados favorables, tanto para los alumnos involucrados como para la comunidad general, por los mensajes que se promueven a través de las publicaciones en plataformas digitales, medios que son muy utilizados por ellos. Además del beneficio del uso de las TIC con fines pedagógicos. 


\section{Recomendaciones}

Resulta necesario que se utilicen estrategias para los cortometrajes como producción audiovisual de manera creativa y colaborativa tales como: La resolución de problema, la socialización, los grupos de discusión grupal, el debate, el role-playing, las grabacionesde cortometrajes, debido a que permiten el aporte de ideas de los estudiantes, identificando distintas vías para llegar a soluciones en consenso. De manera especial, la producción de cortometrajes porque mejora la capacidad del trabajo colaborativo.

Que las prácticas educativas sean colaborativas y que tengan temáticas de carácter social, a fin de que sirvan a los estudiantes para la vida y les permitan a los docentes realizar conexiones entre el contenido que se enseña y la realidad del entorno.

Que se realicen producciones de cortometraje en donde los estudiantes desarrollen diversos roles, ya que esto incentiva la imaginación, la creatividad y el uso adecuado de las TICs con fines pedagógicos.

Que se utilicen los medios de comunicación sociales tales como YouTube, Facebook, WhatsApp, entre otras para publicar y compartir las producciones colaborativas realizadas por los estudiantes, puesto que esta vinculación fomenta su compromiso con la calidad del trabajo académico. Se sugiere el seguimiento constante por parte de los docentes para queel producto a publicar sea apto a los objetivos propuestos.

\section{Referencias}

Arias, F. (2012). El proyecto de investigación. Introducción a la investigación científica. (6ta. Ed.). Editorial Episteme. https://es.slideshare.net/juancarlos777/el-proyecto-deinvestigacion-fidias-arias-2012-6a-edicion 
Calduch, R. (2014). Métodos y técnicas de investigación en relaciones internacionales. Curso de Doctorado. Universidad Complutense de Madrid. https://www.ucm.es/data/cont/media/www/pag-55163/2Metodos.pdf

Elliott, J. (1993). El cambio educativo desde la investigación-acción. Morata. http://chamilo.cut.edu.mx:8080/chamilo/courses/PLANEACIONYDISENOCURRICULAR /document/Elliot-El-Cambio-Educativo-Desde-La-IA.pdf

Fernández del Río, A. y Barreira Arias, A. (2017). El cortometraje como herramienta innovadora para el alumnado con altas capacidades en Educación Primaria. Innoeduca International Journal of Technology and Educational Innovation. 3 (1), 28-36. https://doi.org/10.24310/innoeduca.2017.v3i1.1962

García, J. y Abaurrea, V. (2017). Alumnado con sobredotación intelectual/altas capacidades, Orientaciones para la respuesta educativa. Gobierno de Navarra. Departamento de Educación y Cultura: Pamplona. https://www.educacion.navarra.es/documents/713364/714655/altas_capacidades.pdf/15b2e 313-f8b6-404d-a56d-8cd86e72ae1e

Jarauta, B. (2014). El aprendizaje colaborativo en la universidad: referentes y práctica. Revista de Docencia Universitaria. 12 (4), 281-302. file:///C:/Users/Xuser016/Downloads/5624-181672-PB.pdf

Martínez, M. (2006). Ciencia y Arte de la metodología Cualitativa. Trillas. https://www.academia.edu/29811850/Ciencia_y_Arte_en_La_Metodologia_Cualitativa_M artinez_Miguelez_PDF

Matos de Rojas, Y., Martina Mejia, M., Barreto, Y. y Vethencourt, M. (2018). El trabajo en equipo para promover la participación de los actores sociales. TELOS. Revista de Estudios $\begin{array}{llll}\text { Interdisciplinarios en } \quad \text { Ciencias } & \text { Sociales, }\end{array}$ https://www.thefreelibrary.com/El+trabajo+en+equipo+para+promover+la+participacion+d $\underline{\text { e+los+actores...-a0547622400 }}$ 
Matos, Y., Pasek, E. \& Rojas, Y. (2008). La Investigación como trabajo en equipo desde las experiencias y reflexiones de los actores. Revista Copérnico, IV (8), 03-10. http://revencyt.ula.ve/storage/repo/ArchivoDocumento/copernico/v5n8/art01.pdf

Programa para la Evaluación Internacional de Alumnos, PISA (2015), OCDE 2016. Mejores políticas para una vida mejor. https://www.oecd.org/pisa/pisa-2015-results-in-focus-ESP.pdf Revelo-Sánchez, O., Collazos-Ordóñez, C. y Jiménez-Toledo, J. (2018). El trabajo colaborativo como estrategia didáctica para la enseñanza/aprendizaje de la programación: una revisión $\begin{array}{llllll}\text { sistemática de literatura. } & \text { TecnoLógicas. } & 21 & \text { (41), } & \text { 115-134. }\end{array}$ http://www.scielo.org.co/pdf/teclo/v21n41/v21n41a08.pdf 